\title{
Effects of Short-Term Exposure to Diesel Exhaust on the Ecophysiology, Growth, and Fecundity of Soybean (Glycine $\max ($ L.) Merr.) and Chicory (Cichorium intybus L.)
}

SUSAN Y. JACONIS ', Department of Biological Sciences, University of Cincinnati, Cincinnati, OH, USA; THERESA M. CULLEY, Department of Biological Sciences, University of Cincinnati, Cincinnati, OH, USA; TIMOTHY KEENER, Department of Chemical and Environmental Engineering, University of Cincinnati, Cincinnati, OH, USA [deceased]; ALEXANDRA M. ODOM, University of Virginia Medical Center, Charlottesville, VA, USA; ROBERT ELAM, Department of Biological Sciences, University of Cincinnati, Cincinnati, OH, USA; and MARISSA S. LIANG, National Center for Environmental Assessment, ORD/US EPA, Arlington, VA, USA.

ABSTRACT. Plants growing along roadways are often exposed to vehicle exhaust containing both particulate matter (PM) and various gases that could affect gas exchange and thus plant reproduction. To investigate effects of diesel exhaust exposure on plant ecophysiology, growth, and fecundity, individuals of soybean (Glycine $\max ($ L.) Merr.) and chicory (Cichorium intybus L.) were exposed to either exhaust from a diesel generator or ambient air. Exposure occurred daily over a 5-day period (beginning 18 June 2013) using open-top chambers in an agricultural field in southwestern Ohio, United States. Plants were evaluated at 3 times (before, directly after exposure, and following a 5.5-week post-treatment recovery period) for photosynthetic rate $(A)$, stomatal conductance $(g)$, water use efficiency (WUE), stomatal clogging due to PM deposition, and number of nodes. Aboveground biomass, fruit number, mean seed number, and seed mass were measured for soybean after the recovery period. In soybean, $A$ minimally decreased with exposure to diesel exhaust (compared to the control), but an increase in $g$ and a decrease in WUE were detected after the exhaust treatment. Chicory exhibited a relatively low increase in $A$ after the treatment, but there were no clear differences in $g$ or WUE. Growth and fecundity were similar among all soybean plants directly after treatment, but after 5.5 weeks plants exposed to diesel exhaust had increased vegetative biomass while exhibiting no difference in fecundity. These plant species reacted differently to short-term diesel exhaust exposure, suggesting that the impact of diesel exhaust will depend on both the plant species and its physiology.

\section{INTRODUCTION}

Within their local environment, vascular plant species can reduce ambient pollutants and improve air quality (Manning 2008; Leonard et al. 2016), but the effect of airborne pollutants on plants themselves has been relatively understudied (Mulchi et al. 1992; Ainsworth et al. 2002; Dwivedi and Tripathy 2007). A major anthropogenic source of air pollution in urban areas is vehicular exhaust (e.g., Rai et al. 2010; Vu et al. 2015), which is increasing as vehicle usage escalates worldwide (Bell et al. 2011). One of the major contributors to vehicle exhaust are diesel trucks, which emit gases such as carbon dioxide $\left(\mathrm{CO}_{2}\right)$, carbon monoxide $(\mathrm{CO})$, sulfur dioxide $\left(\mathrm{SO}_{2}\right)$, nitrogen oxides $\left(\mathrm{NO}_{\mathrm{X}}\right)$, and ozone $\left(\mathrm{O}_{3}\right)$ (Rai and Kulshreshtha 2006). Furthermore, diesel

${ }^{1}$ Address correspondence to Susan Y. Jaconis, USA Dry Pea \& Lentil Council, 2780 W. Pullman Road, Moscow, ID 83843-4024, USA. Email: syjaconis@gmail.com trucks produce 50 to 200 times more particulate matter (PM) than the average catalyst gasoline engine (Lunn 2011: p. 153). Both gaseous and particulate pollutants can have a variety of effects on plants (Ashenden et al. 2003; Caporn 2013; Zafar et al. 2016) as these pollutants can affect plant gas exchange processes and growth (González et al. 2014; Li et al. 2019). For example, photosynthesis is highly dependent on $\mathrm{CO}_{2}$ and moisture in the air, and any interruption to gas exchange could interfere with basic photosynthetic reactions. Increased levels of gases like $\mathrm{CO}_{2}$ can also stimulate vegetative plant growth, but this may occur at the expense of fruit production due to differential resource allocation (Reekie and Bazzaz 2005).

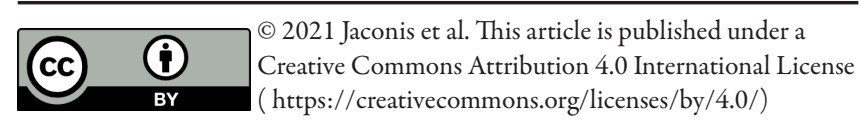


The PM component of diesel exhaust can also negatively impact plant performance, including stunted growth, reduced photosynthetic capabilities, stomatal clogging, and stigma clogging (Thompson et al. 1984; Honour et al. 2009; González et al. 2014; Zeb et al. 2017; Li et al. 2019). The latter could act as a physical block to pollination and therefore hinder fertilization in flowers, leading to reduced seed and fruit production. Stomatal clogging can lead to elevated water loss or impaired water regulation because stomata are unable to open and close properly (Wagner 1939; Zia-Khan et al. 2015; Li et al. 2019). PM and other components of motor vehicle emissions such as $\mathrm{NO}_{\mathrm{X}}$ can have additional effects on plants such as epistomatal wax degradation (Sauter et al. 1987) and epicuticular wax erosion, thus increasing their susceptibility to other gaseous airborne pollutants (Durrani et al. 2004). These gases can also damage stomata, which impairs stomatal regulation and allows further entry of the harmful gases (Kammerbauer and Dick 2000; Durrani et al. 2004).

While the presence of gaseous pollutants may be ephemeral, diesel PM deposition on plants (especially on leaf surfaces) can last for longer periods of time because it is not easily removed by wind and rain (Kulshreshtha et al. 1994). Furthermore, leaf characteristics can play a role in accumulation of PM (González et al. 2014; Leonard et al. 2016; Li et al. 2019). For example, viscid leaves are likely to collect PM more easily and rough leaves can affect the solubility of pollutants (Kumar et al. 2013). Of the few studies investigating effects of PM on a local scale, PM negatively impacts twig growth, transpiration, and photosynthesis; such damage was associated with traffic exposure along roadsides (Kammerbauer and Dick 2000). Rai et al. (2010) and Rai and Kulshreshtha (2006) also demonstrated that leaves of plants grown in polluted locations have an elevated incidence of small stomata among the epidermal cells.

The goal of this study was to quantify the impact of diesel exhaust on plant ecophysiology, growth, and fecundity under relatively controlled conditions. It was hypothesized that these plant measures would be negatively impacted by elevated exposure to diesel exhaust compared to ambient air. Plants in outdoor open-top chambers were subjected to a low dose of diesel exhaust from a generator over 5 days and measured for photosynthetic rate, stomatal conductance, water use efficiency (WUE), plant height, number of leaf nodes, aboveground biomass, and fruit and seed production. To determine if any observed effects were due to potential stomatal clogging by PM, physical adherence of PM to leaf stomata was also quantified.

\section{Location \\ METHODS AND MATERIALS}

The experiment took place during summer 2013 at the University of Cincinnati Center for Field Studies in Harrison, Ohio, approximately $35 \mathrm{~km}$ (22 miles) northwest of the metropolitan area of Cincinnati (lat $39^{\circ} 17^{\prime} 13.91^{\prime} \mathrm{N}$, long $\left.84^{\circ} 44^{\prime} 25.62^{\prime} \mathrm{W}\right)$. The Center is adjacent to agricultural lands and a restored prairie within the Miami Whitewater Forest of the Great Parks of Hamilton County. This site has limited exposure to traffic emissions. From June to August of 2013 , the mean temperature was $27^{\circ} \mathrm{C}$ (range: 6.1 to $36.5^{\circ} \mathrm{C}$ ) with a total of $25 \mathrm{~cm}$ of rainfall.

\section{Study Species}

Soybean (Glycine max (L.) Merr., Fabaceae) is an annual herb that economically is one of the top agricultural crops in Ohio. In this region, soybean fields are often located near roadsides. Plants grow rapidly during spring and summer, eventually producing economically valuable fruits (Libault et al. 2010). Soybean has been used in studies of gaseous pollutants (Heagle et al. 1973; Ainsworth et al. 2002), and $\mathrm{O}_{3}$ is known to reduce its crop yields (Fishman et al. 2010).

Chicory (Cichorium intybus L., Asteraceae) is a herbaceous, weedy herb native to Europe, West Asia, and North Africa, which was introduced to North America. The perennial species has a basal rosette of leaves, often with multiple flowering stalks. Each chicory "flower" is a composite head; plants will bloom continuously during the summer although each flower opens for only a single day. Chicory commonly grows wild along roadsides in the United States and globally, particularly in industrial areas and disturbed sites (Aksoy 2008). Chicory has been used as a phytoindicator in air pollution studies based on its widespread abundance along roadsides (Misik et al. 2006). 


\section{Experimental Design}

A total of 6 outdoor open-top chambers were constructed for the following 2 treatments: (1) exposure to diesel exhaust within a chamber (exhaust treatment) and (2) exposure to ambient air within a chamber (ambient treatment). Plants in an additional control treatment were exposed to ambient air but without chamber walls. There were 3 replicates per treatment type. The chambers were spatially arranged for practicality based on access to the diesel-powered generator. The plants in the non-sided control treatments were positioned south of the exhaust treatment chambers to prevent wind contamination from the exhaust source.

Each open-top chamber was constructed using vertical steel stakes and PVC conduit to create a $2 \mathrm{~m}$ diameter by $1.3 \mathrm{~m}$ tall pentagonal frame (Fig. 1A), which was anchored into the ground. Translucent PVC plastic film (Plastic Film Corporation of America, Romeoville, Illinois) was then wrapped around the frame. The open-top design ensured that the conditions within the interior of the chamber stayed relatively consistent with the surrounding meteorological conditions while still allowing exposure to the treatment. The non-sided control treatment plot was composed of a $2 \mathrm{~m}$ diameter pentagonal area. To minimize herbivory, the control treatment plots were placed within a fenced deer exclosure next to the exhaust and ambient treatment chambers. Prior to commencement of the experiment, minimal rabbit herbivory occurred in the control treatment plots and a mesh fence was then installed to prevent further damage.
To generate diesel exhaust, a portable diesel generator (ETQ-DG4LE, 4000 Watt/3500 Watt, $5.9 \mathrm{HP}$ ), running under full load, was modified with 3 aspirator pumps attached at 120 degrees (and at the same elevation) on an extended stack. This arrangement served to dilute and combine the diesel exhaust with compressed ambient air from 2 air compressors (Porter-Cable ${ }^{\circledR} 13.25$ liter (3.5 gallon) pancake electric air compressor) (Fig. 1A). Diluted exhaust gas from the 3 dilution tubes were tested according to EPA Method 5 (McGaughey et al. 2002) and found to emit an average of $0.0370 \mathrm{~g} / \mathrm{m}^{3}$ total PM. Each of 3 outlet tubes from the aspirator pumps ran into a separate exhaust treatment chamber to discharge the modified air directly downward within each chamber. For each ambient treatment chamber, ambient air ran directly from a second air compressor, with the same air pressure as in the exhaust treatment chambers.

To initially test the effectiveness of the chamber design, PM deposition and temperature were closely monitored during exposure to diesel exhaust. Monitoring PM was accomplished using glass microscope slides covered with petroleum gel and positioned within the chamber. PM deposition on each slide was then quantified using a Nikon ${ }^{\circledR}$ ECLIPSE E200 microscope; mean deposition ranged from 78.4 (highest position) to 145.6 (bottom position) with particulates present across all 4 positions, indicating that PM was circulating within the chamber. Temperatures did not differ appreciably inside or outside the chamber $\left(\mathrm{T}_{\text {inside }}\right.$ $=27.89^{\circ} \mathrm{C}, \mathrm{T}_{\text {outside }}=27.78^{\circ} \mathrm{C}$ ), indicating that diesel

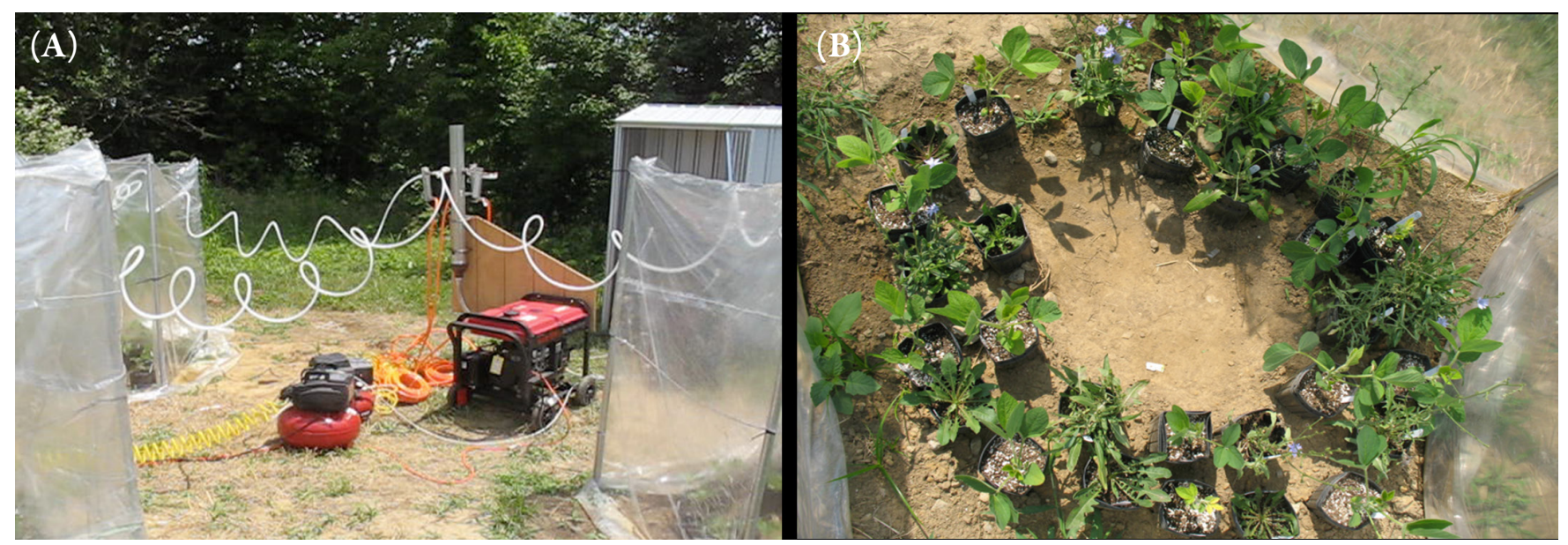

FIGURE 1. Experimental design detailing $(A)$ the generator with exhaust manifold and air compressors used to distribute diesel exhaust to individual chambers and (B) arrangement of soybean (Glycine max) and chicory (Cichorium intybus) plants within an individual chamber. Fifteen potted plants of each species were alternatingly planted in 2 circles around a central drainage point. 
exhaust did not elevate the interior chamber temperature. Before the diesel exhaust exposure period began, mean temperatures within chambers were generally higher (ambient treatment: $33.8^{\circ} \mathrm{C}$, exhaust treatment: $32.1^{\circ} \mathrm{C}$ ) than control treatment plots $\left(27.9^{\circ} \mathrm{C}\right)$. A week after exhaust exposure, mean temperatures were similar in both chambers (ambient treatment: $29.5^{\circ} \mathrm{C}$, exhaust treatment: $\left.29.2^{\circ} \mathrm{C}\right)$ and control treatment plots $\left(29.7^{\circ} \mathrm{C}\right)$.

Each chamber contained 30 plants, divided evenly between the 2 species. There were a total of 135 plants per species across all treatments (exhaust, ambient, and control). Rapidly growing soybeans were germinated from seed (clear hilum organic soybean, Living Whole Foods Inc.) in the greenhouse and transferred to 5-liter volume treepots after their first true leaves appeared. Slower growing chicory plants were collected from a single natural roadside population near the experimental site in May 2013, and immediately potted in 5-liter treepots. All plants were of similar size, grown in soilless growing media (PRO-MIX ${ }^{\circledR}$ HP Mycorrhizae), and kept potted during the experiment to minimize underground root competition. Plants were acclimated outdoors for 2 weeks before treatments began. Potted plants were arranged in 2 circles within each chamber (Fig. 1B), and inserted into the ground $20 \mathrm{~cm}$ deep. Plants were watered daily.

All plants were initially measured 1 day prior to beginning treatments (referred to as before). Treatments then occurred on 5 subsequent weekdays from 18 to 25 June 2013. The experiment was originally planned for exposure over a month period but, unfortunately, it had to be terminated early due to theft of the generator. Plants of both species were then measured immediately (after). Following a subsequent 5.5-week recovery period, soybean plants underwent another round of measurements from 6 to 9 August 2013 (recovery). Soybean was chosen instead of chicory for this last sampling period based on their rapid growth, given time constraints.

\section{Ecophysiology Measures}

Individual plants of soybean and chicory were measured for instantaneous photosynthetic rate $\left(A ; \mu \mathrm{mol} \cdot \mathrm{m}^{-2} \mathrm{~s}^{-1}\right)$, stomatal conductance $(g$; $\mathrm{mmol} \cdot \mathrm{m}^{-2} \mathrm{~s}^{-1}$ ) and water use efficiency (WUE; $\mu \mathrm{mol}_{\mathrm{CO} 2} / \mathrm{mmol}_{\mathrm{H} 2 \mathrm{O}}$; calculated as $A / E$ where $E$ is evapotranspiration) using a LI-COR ${ }^{\circledR}$ LI-6400 infrared gas analyzer (IRGA) (LI-COR Inc., Lincoln, Nebraska). WUE was also calculated as $A / g$, with no appreciable differences (so only $A / E$ is reported here). Measurements were taken between 9:00 AM and 2:00 PM EDT before photosynthetic processes tapered off for the day, and all measurements were completed within 2 days. The IRGA was recalibrated daily with the following settings: air flow, $500 \mu \mathrm{mol} / \mathrm{s}$; sample $\mathrm{CO}_{2}$ concentration, $370 \mu \mathrm{mol}$; leaf temperature, $26^{\circ} \mathrm{C}$; PAR, $1200 \mu \mathrm{mol}$ photons $\mathrm{m}^{-2} \mathrm{~s}^{-1}$; and relative humidity, 45 to $65 \%$. One attached leaf per plant was placed in the sampling chamber and allowed to reach photosynthetic equilibrium. For soybean, the second to distal-most fully expanded leaflet was measured; chicory leaves were selected from the uppermost basal rosette level. Leaves smaller than the sampling chamber area of $6 \mathrm{~cm}^{2}$ were collected and scanned using a LI-COR LI-3100C area meter. Measurements were subsequently adjusted based on this leaf size.

To estimate PM accumulation on leaves, leaf peels were collected from both species before and after exposure to diesel exhaust. Clear nail polish was applied to the top and bottom surface of 1 leaf per plant; after drying, the paint was covered with a clear piece of tape, peeled off, and placed on a microscope slide. Both top and bottom peels were examined microscopically to quantify the percentage of affected stomata. A stoma was classified as clogged if it had at least 1 particulate attached to any portion of the structure.

\section{Plant Growth and Fecundity}

Due to the limited time of the overall experiment, the subsequent research focused on soybean because of its rapid growth rate and fruit production. Before and after the 5-day experimental exposure period, the height of each soybean plant was measured from the soil level to the stem apex, and the number of vegetative nodes was also counted along the main stem. After recovery, abundant growth made these measurements difficult to obtain, so aboveground biomass was used instead. Plants were harvested and transported to the laboratory where they were dried at $32^{\circ} \mathrm{C}$ for 3 days to a constant dry weight, and then weighed (METTLER TOLEDO ${ }^{\circledR}$ AG204 analytical balance, METTLERTOLEDO, Columbus, Ohio). To quantify fecundity, soybean fruits were collected from each plant during harvesting, and seeds were extracted from each fruit. Seeds were weighed in groups of 25 to calculate mean seed mass per plant. 


\section{Data Analysis}

For analysis of the ecophysiological data, effects of the treatment on $A, g$, and $W U E$ were analyzed separately for each species within each sampling period using a nested ANOVA (Sokal and Rohlf 2011) with chamber nested within treatment. If the effect of treatment was found to be significant, post hoc Tukey tests were then used to examine effects of individual treatments. All data conformed to assumptions of normality and heterogeneityexcept for the percentage of clogged stomata, which was analyzed using a Wilcoxon rank sum test with a White modification (Ambrose et al. 2007).

For soybeans only, a nested ANOVA was used to analyze all growth and fecundity traits as described above - with 2 exceptions. First, plant growth (plant height and number of nodes) was compared for each sampling period. Second, aboveground biomass and fecundity (total number of pods, mean seed number, and mean seed mass per plant) was analyzed after the recovery period only. Assumptions of normality were met for all measures, except for mean seed mass which was natural log-transformed.

\section{RESULTS \\ Ecophysiology Measures of Soybean and Chicory \\ Chamber Effects: Because the chamber enclosure} alone could potentially affect ecophysiological performance, this research first compared plant performance within the chamber (ambient treatment) to without (control treatment) at each sampling period (before, after, recovery) (Fig. 2). For chicory, plants in the chambers (ambient treatment and exhaust treatment) exhibited similar photosynthetic rates, stomatal conductance, and WUE as plants in control treatment plots during the before and after sampling periods (Figs. 2D, $2 \mathrm{E}$, and $2 \mathrm{~F}$ ). The only exception was after the treatments, in which $A$ was significantly higher in plants in the ambient treatment than in the exhaust and control treatment groups. In contrast, soybean plants in the chambers consistently exhibited a significant reduction in photosynthetic rates (23 to $29 \%$ lower) and stomatal conductance values (21 to $55 \%$ lower) relative to the open control plots at all 3 sampling periods (before, after, and recovery) (Figs. 2A and 2B). The only exception being that $g$, in plants in the exhaust treatment after recovery, did not show a significant reduction compared to the control treatments. WUE values in soybean were significantly higher in the ambient treatment chambers than in the control treatment plots at the beginning of the experiment (before) $(P<0.05)$; however, plants in the ambient treatment chambers exhibited significantly lower WUE than in control treatment plots $(21 \%$ lower; $P<0.05)$ after exposure. WUE levels in plants in the ambient treatment chamber increased following recovery (Fig. 2C). Overall, WUE across all treatments were similar in chicory (range: 3.17 to $4.90 \mathrm{mmol} / \mathrm{mol}$ ) (Fig. 2F).

Photosynthetic Rate (A): Soybean plants in both the exhaust and ambient treatment groups exhibited similar levels of $A$ before the experiment began (mean Exhaust $=22.22 \mu \mathrm{mol} \mathrm{m} \mathrm{m}^{-2} \mathrm{~s}^{-1}$ and mean $\left._{\text {Ambient }}=23.09 \mu \mathrm{mol} \mathrm{m} \mathrm{m}^{-2} \mathrm{~s}^{-1}\right)$, directly after exposure $\left(\operatorname{mean}_{\text {Exhaust }}=21.23 \mu \mathrm{mol} \mathrm{m} \mathrm{m}^{-2} \mathrm{~s}^{-1}\right.$ and mean $\left._{\text {Ambient }}=20.62 \mu \mathrm{mol} \mathrm{m} \mathrm{m}^{-2} \mathrm{~s}^{-1}\right)$ and following the recovery period $\left(\operatorname{mean}_{\text {Exhaust }}=18.51 \mu \mathrm{mol} \mathrm{m} \mathrm{m}^{-2} \mathrm{~s}^{-1}\right.$ and $\operatorname{mean}_{\text {Ambient }}=15.13 \mu \mathrm{mol} \mathrm{m} \mathrm{m}^{-2} \mathrm{~s}^{-1}$ ) (Fig. 2A). Photosynthetic rates for soybean in the control treatment were statistically higher than in the ambient and exhaust treatments in all sampling periods (before: $F_{[2,92]}=15.69, P<0.0001$; after: $F_{[2,126]}=32.94, P<0.0001$; recovery: $F_{[2,85]}=29.04$, $P<0.0001$ ) (Fig. 2A).

At the start of the experiment, chicory plants in the 3 treatment groups did not differ in $A$ (mean $_{\text {Exhaust }}=$ $22.15 \mu \mathrm{mol} \mathrm{m}^{-2} \mathrm{~s}^{-1}$, mean $_{\text {Ambient }}=23.76 \mu \mathrm{mol} \mathrm{m}^{-2} \mathrm{~s}^{-1}$, and mean $_{\text {Control }}=24.32 \mu \mathrm{mol} \mathrm{m}{ }^{-2} \mathrm{~s}^{-1} ; F_{[2,122]}=0.85$, $P=0.4306$ ) (Fig. 2D). After the treatment period, however, chicory plants in the exhaust treatment exhibited significantly lower values of $A(27.40 \mu \mathrm{mol}$ $\left.\mathrm{m}^{-2} \mathrm{~s}^{-1}\right)$ than plants in the ambient treatment $(36.32$

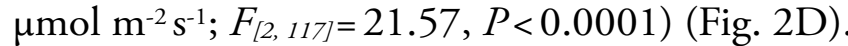

Stomatal Conductance (g) and Potential Clogging: Soybean plants in the exhaust and ambient treatment groups exhibited similar values of $g$ prior to the start of the treatments (mean Exhaust $=0.415$ $\mathrm{mmol} \mathrm{m}^{-2} \mathrm{~s}^{-1}$ and mean $_{\text {Ambient }}=0.383 \mathrm{mmol} \mathrm{m}^{-2} \mathrm{~s}^{-1}$ ) (Fig. 2B). By the conclusion of the treatment, exhaust treatment plants had significantly greater values of $g$ $\left(0.663 \mathrm{mmol} \mathrm{m}^{-2} \mathrm{~s}^{-1}\right)$ than in the ambient treatment group $\left(0.493 \mathrm{mmol} \mathrm{m}^{-2} \mathrm{~s}^{-1} ; P<0.05\right)$. This continued into the recovery period $\left(\operatorname{mean} n_{\text {Exhaust }}=0.739\right.$ $\mathrm{mmol} \mathrm{m} \mathrm{m}^{-2} \mathrm{~s}^{-1}$ and mean Ambient $=0.356 \mathrm{mmol} \mathrm{m}^{-2} \mathrm{~s}^{-1}$; $P<0.05)$. In chicory, plants within the exhaust and ambient treatments exhibited similar levels of $g$ before (mean Exhaust $=0.452 \mathrm{mmol} \mathrm{m}^{-2} \mathrm{~s}^{-1}$ and mean $_{\text {Ambient }}=0.324 \mathrm{mmol} \mathrm{m} \mathrm{ms}^{-1} ; F_{[2,120]}=2.74$, 
$P=0.068$ ) (Fig. 2E) and after the treatment $\left(\right.$ mean $_{\text {Exhaust }}=0.705 \mathrm{mmol} \mathrm{m}^{-2} \mathrm{~s}^{-1}$ and mean Ambient $=$ $0.853 \mathrm{mmol} \mathrm{m}^{-2} \mathrm{~s}^{-1} ; F_{[2,117]}=1.39, P=0.2525$ ) (Fig. $2 \mathrm{E})$. However, conductance approximately doubled over time in both groups (Fig. 2E).

Stomatal clogging was minimal, as few stomata were blocked by PM. According to the Wilcoxon test, no significant differences in the percentage of clogged stomata were detected before or after exposure to diesel exhaust for the top or bottom of the leaves $(P>0.05)$. For example, none of the stomata on the bottom of soybean leaves were blocked by PM before exposure to diesel exhaust and, following the treatment, only 2 plants in the chambers experienced clogged stomata $(Z=0.359, P>0.05)$.

Water Use Efficiency (WUE): Prior to exposure, soybean plants in the exhaust treatment group exhibited significantly lower levels of WUE (mean $\left.=3.48 \mu \mathrm{mol}_{\mathrm{CO} 2} / \mathrm{mmol}_{\mathrm{H} 2 \mathrm{O}}\right)$ compared to the ambient treatment group (mean $=4.28$; Tukey test: $P<0.05)$ (Fig. 2C). This difference continued after the experimental treatments over the 5-day period, with soybean plants in the exhaust treatment having reduced levels of WUE (mean $=2.30)$ compared to ambient treatment plants (mean $=2.57$; Tukey test: $P<0.05)$. By the end of the recovery period, however, levels of WUE in soybean had rebounded slightly, but still with similar values between the 2 groups $\left(\right.$ mean $_{\text {Exhaust }}=2.81 ;$ mean $\left._{\text {Ambient }}=3.00\right)($ Fig. 2C). In contrast, in chicory there was no significant difference in WUEbetween the ambient and exhaust treatments before and after the treatment $(P>0.05)$ (Fig. 2F). Overall, WUE values decreased during the measuring period.
Glycine max

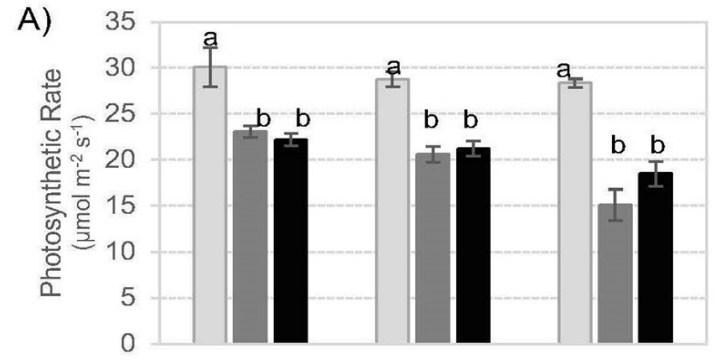

B)

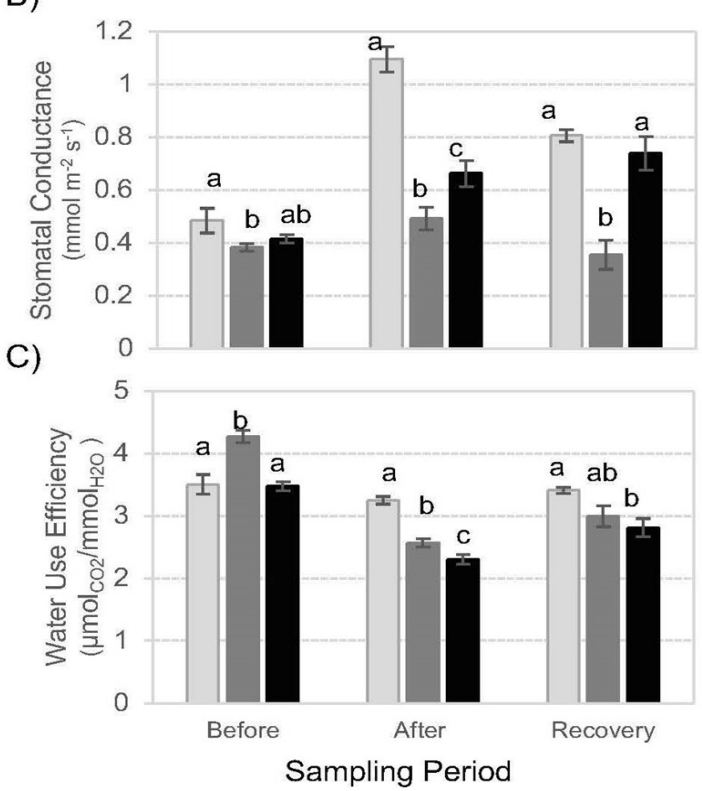

Cichorium intybus

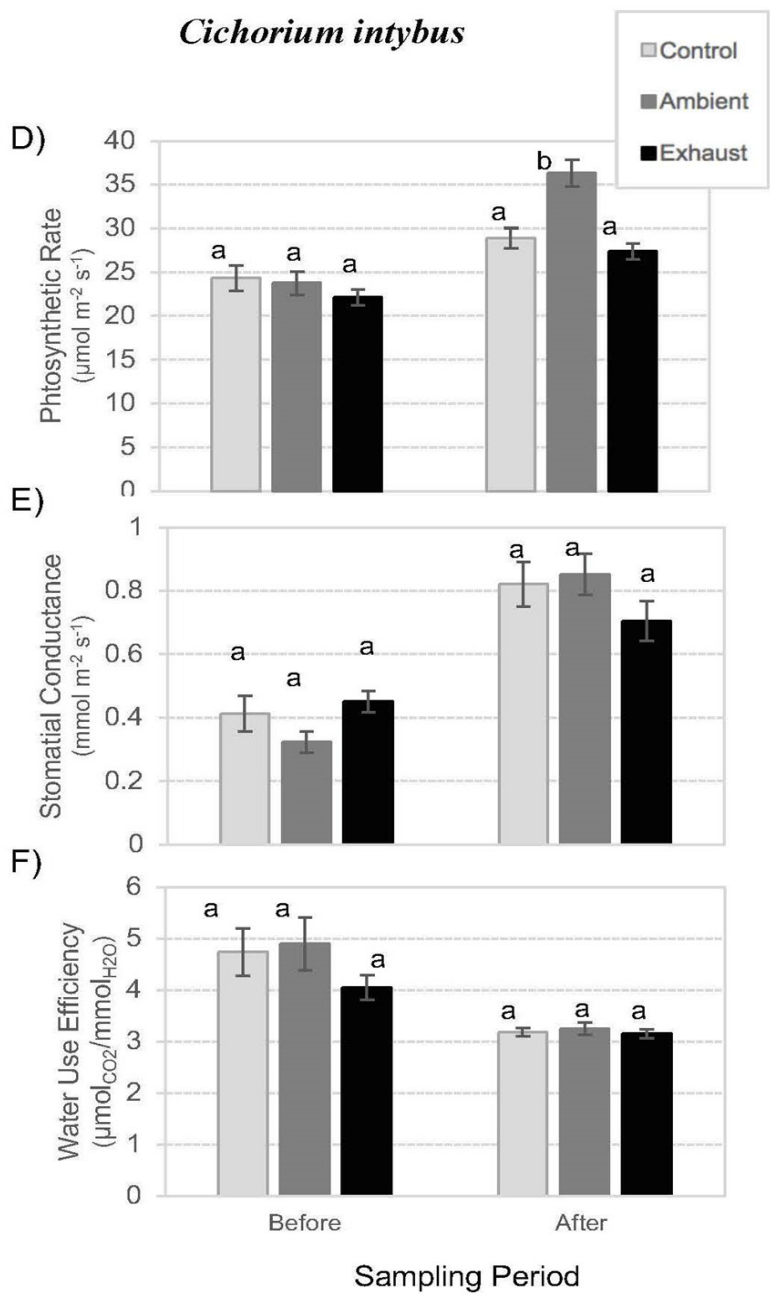

FIGURE 2. Mean ecophysiological values for each sampling period for soybean (Glycine max) (left column) and chicory (Cichorium intybus) (right column). Shown for each species are mean values of instantaneous photosynthetic rate (top panels: A, D), stomatal conductance (middle panels: B,E), and water use efficiency (bottom panels: C, F). Significant differences among treatments within each sampling period are indicated by different letters. Measurements were taken during the before, after, and recovery periods for soybean and the before and after sampling periods for chicory. Error bars indicate the standard error of each mean value. 


\section{Plant Growth and Fecundity of Soybean}

To determine whether the chamber structure alone may affect traits in soybean, the performance of plants within the control and ambient treatment groups, for each sampling period, were compared (Fig. 3).

Plants inside the chambers (ambient) typically exhibited higher growth and fecundity compared to the control treatment. Even before exposure to diesel exhaust had begun (before), plants grown in chambers for 2 weeks were already significantly taller (mean $=10.7 \mathrm{~cm}$ ) and contained more nodes (mean $=2.48$ ) than control treatment plants growing outside of the chambers $(6.1 \mathrm{~cm}$ and 2.02 nodes, respectively; $P<0.0001$ for both comparisons). This trend continued after the 5-day exposure to diesel exhaust. Plants in the chambers were on average $55 \%$ taller than control treatment plants $\left(F_{[2,126]}=131.0, P<0.0001\right)$. However, these growth differences disappeared by the end of the recovery period, with similar mean aboveground biomass in the control (20.3 g) and ambient $(21.7 \mathrm{~g})$ treatments. Also by the end of the recovery period, plants in chambers exhibited significantly lower numbers of fruits containing smaller seeds (Figs. 4B and $4 \mathrm{C}$ ), with a non-significant decrease in the mean number of seeds per fruit $\left(\right.$ mean $_{\text {Control }}=2.6$ seeds; mean $_{\text {Ambient }}=2.5$ seeds) (Fig. $4 \mathrm{~A}$ ). Plants grown in chambers produced fewer fruits $\left(\operatorname{mean}_{\text {Ambient }}=42.9\right)$ than control treatment plants growing outside of the chambers $\left(\right.$ mean $_{\text {Control }}=55.8$ fruits) $($ Fig. $4 \mathrm{C})$.

\section{Plant Height, Node Number, and Biomass}

Prior to exposure to the experimental treatments, soybean plants in the ambient and exhaust treatment categories were of similar height $(P>0.05)$ (Fig. $3 \mathrm{~A})$ and had a similar number of nodes $(P>0.05)$ (Fig. 3B). These similarities did not change after plants had more than doubled in size after the experimental treatments; plants exposed to diesel exhaust over 5 days were still similar in terms of height $(24.7 \mathrm{~cm})$ and number of nodes $(7.04)$ as plants exposed to ambient air $(25.4 \mathrm{~cm}$ and 7.62 nodes) (Figs. 3A and 3B). Within each treatment (control, ambient, and exhaust), plant height and node number significantly increased over time (for all comparisons: $P<0.0001$ ) as plants grew rapidly in the days before and after exposure to the treatments. Following recovery, soybeans in the exhaust treatment had $28 \%$ and $22 \%$ greater biomass than plants in the control and ambient treatments $\left(F_{[2,81]}=7.151, P=0.034\right)$ (Fig. 3C), despite the fact that the initial exposure length was only 5 days.

\section{Fruit and Seed Production}

By the end of the recovery period, soybean plants in the ambient and exhaust treatments were similar in terms of mean seed mass $(21.2$ and $21.4 \mathrm{mg}$, respectively; $\left.F_{[2,126]}=0.725, P=0.522\right)($ Fig. $4 \mathrm{~B})$ and number of fruits (42.9 and 47.8, respectively; $\left.F_{[2,126]}=1.381, P=0.321\right)$ (Fig. 4C). The average number of seeds per fruit ranged from 2.52 to 2.60 in plants in ambient and exhaust treatments $\left(F_{[2,126]}=0.764, P=0.506\right)($ Fig. $4 \mathrm{~A})$.
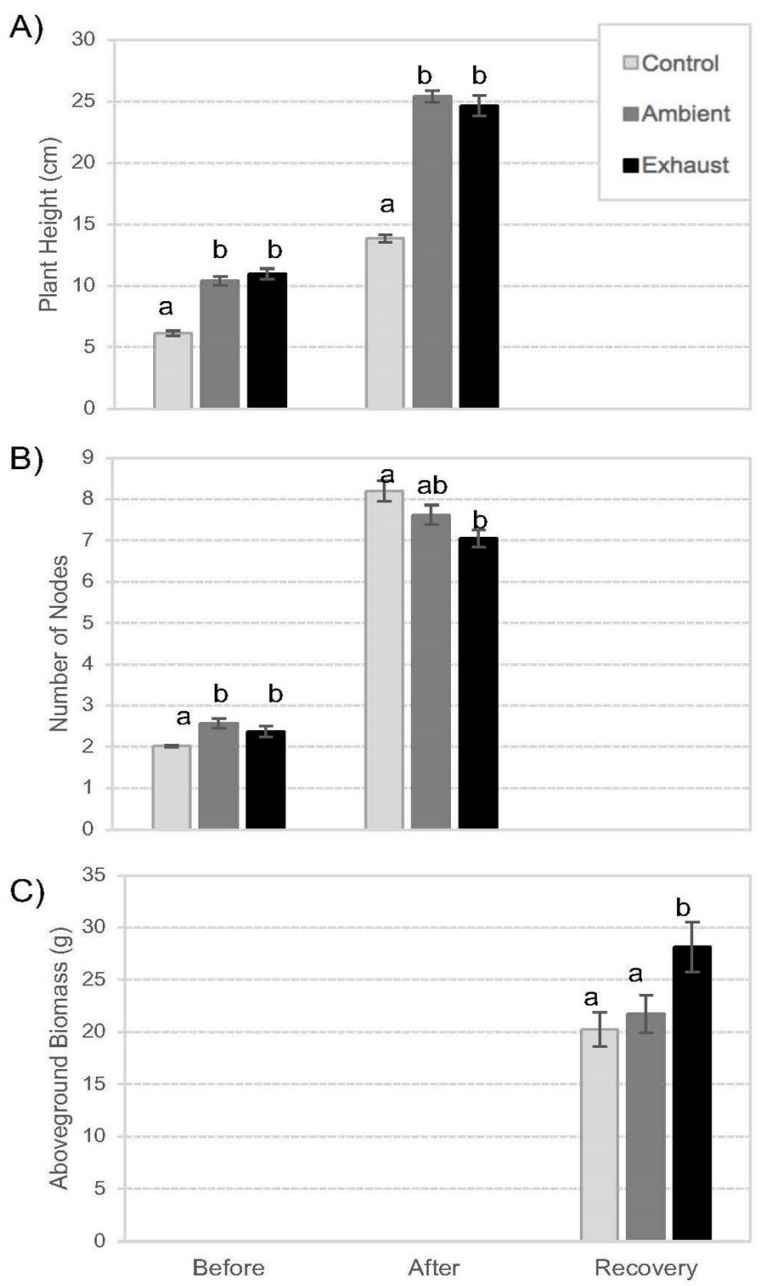

FIGURE 3. Mean values for plant growth for soybean (Glycine $\max$ ) in the 3 experimental treatment groups (control, ambient, exhaust). Shown are (A) plant height and (B) number of nodes measured at the before and after sampling periods, based on $\mathbf{4 5}$ plants per treatment. Plant growth was so substantial by the end of the recovery period that aboveground biomass (C) was used instead as an estimate of plant growth. Significant differences among treatments within each sampling period are indicated by different letters. Error bars indicate the standard error of each mean value. 


\section{DISCUSSION}

If diesel exhaust negatively impacts plant ecophysiology, growth, and fecundity, plants exposed to diesel exhaust should exhibit lower values of these measures compared to those exposed to ambient air. Furthermore, if these plant species are able to overcome negative impacts from pollutant exposure, there should be an eventual recovery in which subsequent measurements (in the absence of the pollutant) should rebound to previous values. Even though the exposure period to diesel exhaust was unexpectedly shortened to only 5 days, this amount of time was still enough to result in some significant declines in soybean and chicory traits
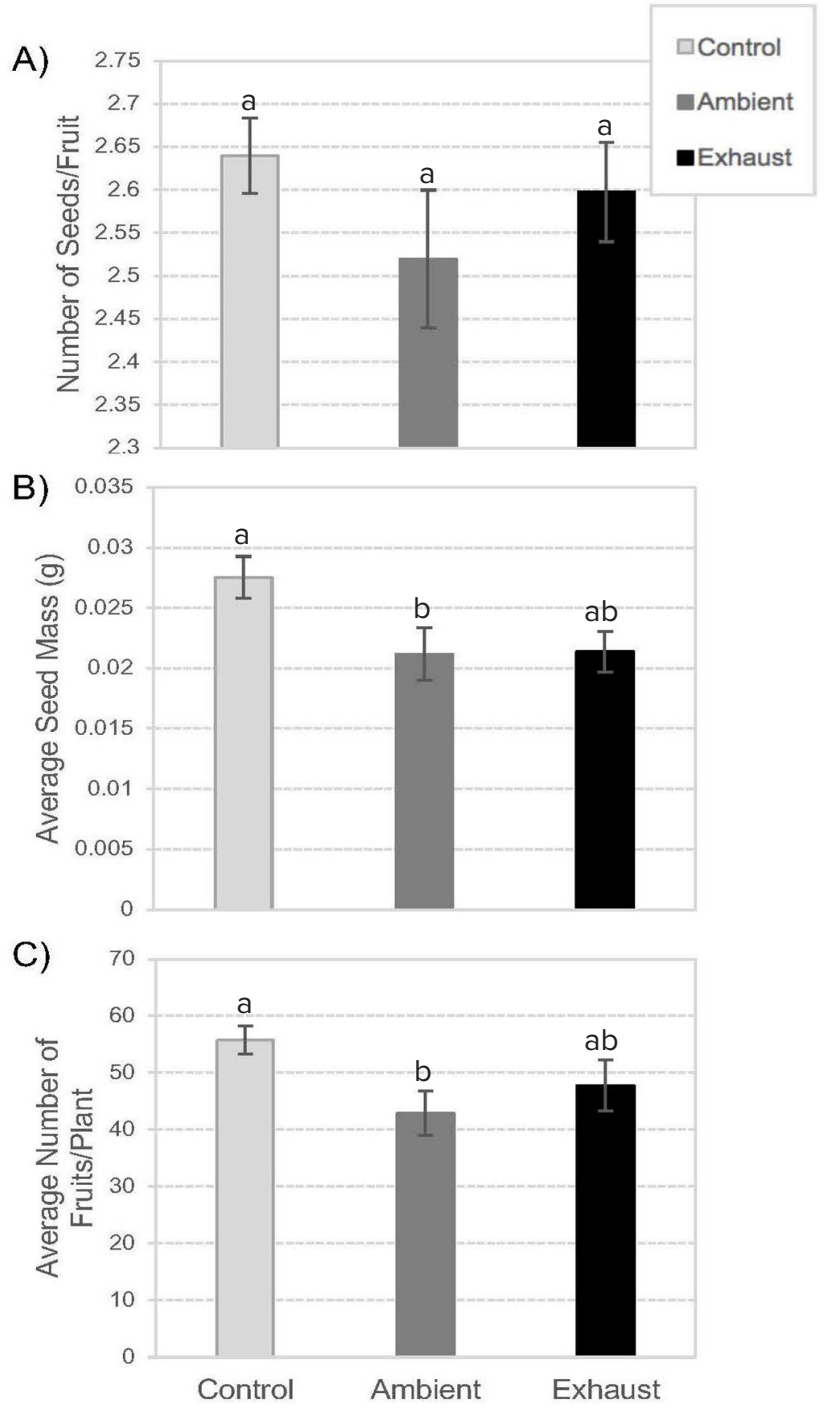

FIGURE 4. Mean values for fecundity of soybean (Glycine max) after the recovery period at the conclusion of the study in the 3 experimental treatment groups (control, ambient, exhaust). Shown are (A) number of seeds per pod (fruit), (B) mean seed mass per plant, and (C) mean number of pods per plant. Significant differences among treatments within each sampling period are indicated by different letters. Error bars indicate the standard error of each mean value. There were 45 plants within each treatment. (see also Li et al. 2019), although the direction was not always consistent. WUE in soybean decreased significantly with exposure to diesel exhaust before rebounding back to near-previous levels after the recovery period, as expected (Fig. 2C). However, a similar pattern was not seen in $A$ or $g$ for the same species. In chicory, plants exposed to diesel exhaust exhibited significantly lower values of $A$ but not of $g$ or WUE. In soybean, diesel exhaust exposure did not affect plant height or number of nodes, but diesel exhaust exposure did have a positive effect on aboveground biomass (Fig. 3). After the recovery period, there was no difference in number of seeds per fruit, seed mass, or number of fruits in soybean plants exposed to diesel exhaust or ambient air (Fig. 4). This created a lower fruit to biomass ratio due to the greater biomass of the plants exposed to diesel exhaust. In general, impacts of exposure to diesel exhaust varied according to species and direction of the effect, consistent with Leonard et al. (2016).

Given the preponderance of reported negative effects of diesel exhaust and particulates on plant health and fitness (Thompson et al. 1984; Kammerbauer and Dick 2000; Honour et al. 2009; González et al. 2014; Li et al. 2019), there are several possible reasons why impacts were not consistently seen in all measured traits in soybean and chicory. First, an exposure longer than 5 days, or heavier loads of diesel exhaust, may be necessary to have a measurable impact on plant ecophysiology, growth, and fecundity. Kammerbauer and Dick (2000) exposed plants in the field to 5 months of urban traffic exhaust exposure, and González et al. (2014) examined plants that had been naturally exposed to PM for over 1 year: both studies allowed more time for accumulation of deleterious effects. Additionally, Thompson et al. (1984) used controlled laboratory and glasshouse experiments to detect reduced photosynthetic capability in leaves exposed to 5 to $10 \mathrm{~g} / \mathrm{m}^{2}$ of manually added car exhaust dust - much higher than typical roadway dust loads (Pirjola et al. 2010). However, Li et al. (2019) used indoor chambers to expose 4 plant species to different levels of $\mathrm{PM}_{2.5}$ over only a 10 -hour period; despite this very short exposure period, they detected declines in photosynthetic rate and stomatal conductance with increased PM exposure. Consequently, the exposure time of the current study-although certainly not ideal-does indicate that soybean and chicory can experience negative impacts of diesel exhaust exposure. 
It is also possible that the ecophysiological and growth traits in soybean and chicory responded to different components of the diesel exhaust. The fact that there was no effect of diesel exhaust on the percentage of obstructed stomata in chicory and soybean suggests that substantial amounts of PM did not accumulate on the leaves during the duration of the project, although PM was readily detected within the airflow. In studies of PM deposition, stomata were not always blocked but photosynthetic rates still declined-indicating that PM may have been absorbed through the stomate into the leaf itself (Li et al. 2019). In the current study, the observed impacts on plant ecophysiology may have been primarily due to the gaseous component of the diesel exhaust. In particular, $\mathrm{CO}_{2}$ is known to directly increase photosynthetic activity in plants (Tai et al. 2010). The $\mathrm{CO}_{2}$ may have offset any disadvantages caused by other gases $\left(\mathrm{SO}_{\mathrm{X}}\right.$ and $\left.\mathrm{NO}_{\mathrm{X}}\right)$ that decrease photosynthesis (Saxe and Christensen 1985; Rai and Kulshreshtha 2006). The fast-growing soybean may have been able to incorporate more $\mathrm{CO}_{2}$ when exposed to diesel exhaust, thereby overcoming any reduction in photosynthetic rate (Fig. 2A); this same effect may not have occurred in the slowergrowing chicory (Fig. 2D). Unfortunately, gases present in the exhaust treatment could not be quantified because the diesel generator was stolen before additional measurements could be made.

Soybean and chicory may have also differed in their responses to diesel exhaust exposure simply because of their different life history strategies and environmental tolerances. Soybean is cultivated in well-watered agricultural fields and produces fruits after only a few weeks of rapid vegetative growth. In contrast, chicory is a slow-growing, weedy, perennial species with a basal rosette and deep taproot — enabling it to persist for years along the harsh environment of active roadways. These different life history strategies are consistent with the observation that soybean appeared to be more sensitive to diesel exhaust than chicory. Because soybean plants were first exposed to treatments as seedlings (as opposed to adult individuals of chicory transplanted from the wild), their ecophysiology may have been more sensitive to diesel exhaust due to their young age (such as for WUE). Additionally, soybean produce many compound leaves, thus having greater leaf area per plant; chicory produces only a basal rosette of leaves with few thin, serrated leaves. These vegetative differences may help explain the higher photosynthetic rates in chicory if $A$ is measured per unit area of the leaf. It remains to be seen if $A$ calculated over the entire soybean plant may actually be higher than in chicory individuals, given the greater total leaf area of the soybean plant (see Medrano et al. 2015).

Moreover, the lack of ecophysiological differences among chicory in the ambient and exhaust treatments may reflect the possibility that chicoryas a common roadside plant — is already adapted to polluted conditions. Dwivedi and Tripathi (2007) investigated the air pollution tolerance index (APTI) of various plant species surrounding industrial sites based on their tolerance to $\mathrm{SO}_{\mathrm{X}}, \mathrm{NO}_{\mathrm{X}}$, and PM. They found that plants with lower APTI inhabited less-polluted locations, with plants within the Fabaceae having a lower average APTI than those of the Asteraceae family. If soybean and chicory are representative of their families, chicory should have a greater threshold to air pollution-which is consistent with results of the current study.

It is noteworthy that, in both species, $g$ within the chambers increased after the exhaust treatment (Figs. 2B and 2E). Although $g$ is expected to increase with plant growth, previous air pollution studies showed that conductance is often reduced following exposure (Nighat et al. 2000; McAinsh et al. 2002; Onandia et al. 2011). This was not consistent with the current findings, which may be related to the fact that plants were kept well-watered within the chambers. In chicory, this may have led to greater stomatal conductance as stomata were kept open, which is consistent with higher $A$ but a lower WUE. Higher $g$ may allow for greater intake of $\mathrm{CO}_{2}$ in response to elevated $\mathrm{CO}_{2}$ present in the diesel exhaust.

Finally, it is possible that the chamber structure alone may have inadvertently influenced the ecophysiology of soybean (Figs. 2A and 2B) but not of chicory (Fig. 2D and 2E) during the experiment. In soybean, $A$ and $g$ were generally depressed within chambers, compared to control treatment plots. As a rapidly growing crop that requires frequent water, soybean may have been negatively impacted by the higher evapotranspiration towards the end of the day as the chamber warmed up, unless plants could begin photosynthesizing earlier. Consequently, soybean plants grown in chambers for 2 weeks before exposure to diesel exhaust were already $43 \%$ taller and contained 18\% more nodes than control treatment plants growing outside of the 
chambers. Soybean plants in the control treatment plots also produced significantly more fruits per plant with greater seed mass, but with the same number of seeds as plants in chambers at the end of the recovery period. In contrast, chicory did not appear to be negatively affected by being enclosed in the chambers, most likely because the species is slow-growing and, as a common roadside plant, may already be adapted to stressful environments.

\section{Conclusions}

Despite exposure of plants to diesel exhaust over only a 5-day period, measurable impacts of diesel exhaust were detected in some ecophysiological and plant growth traits-but not always in a negative direction. These results have important implications for agriculture, especially as farm equipment is often diesel powered. Previous studies have suggested that plant yields, and even nutritional content, could be negatively impacted by air pollution (Rai and Kulshreshtha 2006), and the current study also demonstrated lower fruit to aboveground biomass ratios in soybean following diesel exhaust exposure. Although future studies must increase the exposure period, the current results at least suggest that even limited exposure to diesel exhaust may negatively impact crop production of some species. Knowing and understanding the type and extent of effects due to gaseous and particulate air pollutant exposure will help biologists, crop breeders, and horticulturalists optimize plant performance. While urban plant species can reduce airborne PM concentrations (Song et al. 2015), further research is needed to investigate the effects of diesel exhaust in real world urban conditions, especially in areas where crops and other plant species are grown near transportation corridors.

\section{ACKNOWLEDGEMENTS}

We would like to thank Drs. Mingming Lu, Jodi Shann, Ishi Buffam, and David Lentz for their input during this project, and Kala Stephens, Cameron Brown, Natashia Pierce, Zach Mergenthal, Paul Wilcox, Elysam Raib, and Rina Raib for their invaluable assistance with measurements. This project was funded by the University of Cincinnati's Benedict Award, Wendel Botany Award, and Wieman Wendel Benedict Awards and the Botanical Society of America's Student Research Award and the University of Cincinnati's Graduate Student Governance Association.

\section{LITERATURE CITED}

Ainsworth EA, Davey PA, Bernacchi CJ, Dermody OC, Heaton EA, Moore DJ, Morgan PB, Naidu SL, Yoo Ra HS, Zhu XG, Curtis PS, Long SP. 2002. A meta-analysis of elevated $\left[\mathrm{CO}_{2}\right]$ effects on soybean (Glycine max) physiology, growth and yield. Global Change Biol. 8(8):695-709.

https://doi.org/10.1046/j.1365-2486.2002.00498.x

Aksoy A. 2008. Chicory (Cichorium intybus L.): a possible biomonitor of metal pollution. Pakistan J Bot. 40(2):791-797.

Ambrose HW 3rd, Peckham Ambrose K, Emlen DJ, Bright KL. 2007. A handbook of biological investigation. 7th ed. Winston-Salem (NC): Hunter Textbooks. ISBN 13: 9780887253317.

Ashenden TW, Ashmore M, Bell JNB, Bingal K, Binnie J, Cape JN, Caporn SJM, Carroll J, Davidson A, Hadfield P, Honour S, Lawton K, Moore S, Power S, Shields C. 2003. Impacts of vehicle emissions on vegetation. Trans Built Environ. 64:313-322.

Bell JNB, Honour SL, Power SA. 2011. Effects of vehicle exhaust emissions on urban wild plant species. Environ Pollut. 159(8-9):1984-1990.

https://doi.org/10.1016/j.envpol.2011.03.006

Caporn SJM. 2013. Ecophysiological responses of plants to air pollution. In: eLS. Hoboken (NJ): John Wiley \& Sons Inc. https://doi.org/10.1002/9780470015902.a0003206.pub2

Durrani GF, Hassan M, Baloch MK, Hameed G. 2004. Effect of traffic pollution on plant photosynthesis. J Chem Soc Pakistan. 26(2):176-179.

https://jcsp.org.pk/ArticleUpload/1316-5959-1-PB.pdf

Dwivedi AK, Tripathi BD. 2007. Pollution tolerance and distribution pattern of plants in surrounding area of coalfired industries. J Environ Biol. 28(2):257-263. PMID: 17915761

Fishman J, Creilson JK, Parker PA, Ainsworth EA, Vining GG, Szarka J, Booker FL, Xu X. 2010. An investigation of widespread ozone damage to the soybean crop in the upper Midwest determined from ground-based and satellite measurements. Atmos Environ. 44(18):2248-2256. https://doi.org/10.1016/j.atmosenv.2010.01.015

GonzálezJA, Prado FE, Piacentini RD. 2014. Atmospheric dust accumulation on native and non-native species: effects on gas exchange parameters. J Environ Qual. 43(3):801-808. https://doi.org/10.2134/jeq2013.08.0308

Heagle AS, Body DE, Heck WW. 1973. An open-top field chamber to assess the impact of air pollution on plants. J Environ Qual. 2(3):365-368.

https://doi.org/10.2134/jeq1973.00472425000200030014x

Honour SL, Bell JNB, Ashenden TW, Cape JN, Power SA. 2009. Responses of herbaceous plants to urban air pollution: effects on growth, phenology and leaf surface characteristics. Environ Pollut. 157(4):1279-1286. https://doi.org/10.1016/j.envpol.2008.11.049

Kammerbauer J, Dick T. 2000. Monitoring of urban traffic emissions using some physiological indicators in Ricinus communis L. plants. Arch Environ Con Tox. 39(2):161-166. https://doi.org/10.1007/s002440010092 
Kulshreshtha K, Farooqui A, Srivastava K, Singh SN, Ahmad KJ, Behl HM. 1994. Effect of diesel exhaust pollution on cuticular and epidermal features of Lantana camara L. and Syzygium cuminii L. (Skeels). J Environ Sci Heal A. 29(2):301-308. https://doi.org/10.1080/10934529409376037

Kumar SR, Arumugam T, Anandakumar CR, Balakrishnan S, Rajavel DS. 2013. Use of plant species in controlling environmental pollution-a review. Bull Environ Pharm Life Sci. 2(2):52-63.

Leonard RJ, McArthur C, Hochuli DF. 2016. Particulate matter deposition on roadside plants and the importance of leaf trait combinations. Urban For Urban Gree. 20:249-253. https://doi.org/10.1016/j.ufug.2016.09.008

Li Y, Wang Y, Wang B, Wang Y, Yu W. 2019. The response of plant photosynthesis and stomatal conductance to fine particulate matter $\left(\mathrm{PM}_{2.5}\right)$ based on leaf factors analyzing. J Plant Biol. 62:120-128. https://doi.org/10.1007/s12374-018-0254-9

Libault M, Farmer A, JoshiT, Takahashi K, Langley RJ, Franklin LD, He J, Xu D, May G, Stacey G. 2010. An integrated transcriptome atlas of the crop model Glycine max, and its use in comparative analyses in plants. Plant J. 63(1):86-99. https://doi.org/10.1111/j.1365-313X.2010.04222.x

Lunn RM, director, Report on Carcinogens Center. 2011. Twelfth report on carcinogens. Research Triangle Park (NC): US Department of Health and Human Services, Public Health Service, National Toxicology Program. p. 153-156.

Manning WJ. 2008. Plants in urban ecosystems: essential role of urban forests in urban metabolism and succession toward sustainability. Int J Sust Dev World. 15(4):362-370. https://doi.org/10.3843/SusDev.15.4:12

McAinsh MR, Evans NH, Montgomery LT, North KA. 2002. Calcium signaling in stomatal responses to pollutants. New Phytol. 153(3):441-447. https://doi.org/10.1046/j.0028-646X.2001.00336.x

McGaughey JF, Merrill RG Jr, Bursey JT, Wagoner DE, Jackson MD, Johnson LD. 2002. Preparation of the components of the modified method 5 (method 0010) sampling train for analysis by SW-846 method 8270. Washington (DC): US Environmental Protection Agency, Air Emission Measurement Center. EPA Report No.: EPA/600/A-94/098.

Medrano H, Tomás M, Martorell S, Flexas J, Hernández E, Rosselló J, Pou A, Escalona JM, Bota J. 2015. From leaf to whole-plant water use efficiency (WUE) in complex canopies: limitations of leaf WUE as a selection target. Crop J. 3(3):220-228.

https://doi.org/10.1016/j.cj.2015.04.002

Misik M, Solenska M, Micieta K, Misikova K, Knasmuller S. 2006. In situ monitoring of clastogenicity of ambient air in Bratislava, Slovakia using the Tradescantia micronucleus assay and pollen abortion assays. Mutat Res-Gen Tox En. 605(1-2):1-6.

https://doi.org/10.1016/j.mrgentox.2005.12.009

Mulchi CL, Slaughter L, Saleem M, Lee EH, Pausch R, Rowland R. 1992. Growth and physiological characteristics of soybean in open-top chambers in response to ozone and increased atmospheric $\mathrm{CO}_{2}$. Agr Ecosyst Environ. 38(1-2):107-118. https://doi.org/10.1016/0167-8809(92)90172-8
Nighat F, Mahmooduzzafar, Iqbal M. 2000. Stomatal conductance, photosynthetic rate, and pigment content in Ruellia tuberosa leaves as affected by coal-smoke pollution. Biol Plantarum. 43(2):263-267. https://doi.org/10.1023/A:1002712528893

Onandia G, Olsson AK, Barth S, King JS, Uddling J. 2011. Exposure to moderate concentrations of tropospheric ozone impairs tree stomatal response to carbon dioxide. Environ Pollut. 159(10):2350-2354. https://doi.org/10.1016/j.envpol.2011.06.001

Pirjola L, Johansson C, Kupiainen K, Stojiljkovic A, Karlsson H, Hussein T. 2010. Road dust emissions from paved roads measured using different mobile systems. J Air Waste Manage. 60(12):1422-1433. https://doi.org/10.3155/1047-3289.60.12.1422

Rai A, Kulshreshtha K. 2006. Effect of particulates generated from automobile emission on some common plants. J Food Agric Environ. 4(1):253-259.

Rai A, Kulshreshtha K, Srivastava PK, Mohanty CS. 2010. Leaf surface structure alterations due to particulate pollution in some common plants. Environmentalist. 30(1):18-23. https://doi.org/10.1007/s10669-009-9238-0

Reekie EG, Bazzaz FA. 2005. Reproductive allocation in plants. Cambridge (MA): Academic Press (an imprint of Elsevier). 264 p. ISBN 13: 9780120883868. https://doi.org/10.1016/B978-0-12-088386-8.X5000-5

Sauter JJ, Kammerbauer H, Pambor L, Hock B. 1987. Evidence for the accelerated micromorphological degradation of epistomatal waxes in Norway spruce by motor vehicle emissions. Eur J Forest Pathol. 17(7):444-448. https://doi.org/10.1111/j.1439-0329.1987.tb01122.x

Saxe H, Christensen OV. 1985. Effects of carbon dioxide with and without nitric oxide pollution on growth, morphogenesis and production time of pot plants. Environ Pollut A. 38(2):159-169. https://doi.org/10.1016/0143-1471(85)90074-1

Sokal RR, Rohlf FJ. 2011. Biometry. 4th ed. New York (NY): W.H. Freeman. 960 p. ISBN 13: 9780716786047

Song Y, Maher BA, Li F, Wang X, Sun X, Zhang H. 2015. Particulate matter deposited on leaf of five evergreen species in Beijing, China: source identification and size distribution. Atmos Environ. 105:53-60. https://doi.org/10.1016/j.atmosenv.2015.01.032

Tai HH, Percy KE, Karnosky DF. 2010. DNA damage in Populus tremuloides clones exposed to elevated $\mathrm{O}_{3}$. Environ Pollut. 158(4):969-976. https://doi.org/10.1016/j.envpol.2009.10.005

Thompson JR, Mueller PW, Fluckiger W, Rutter AJ. 1984. The effect of dust on photosynthesis and its significance for roadside plants. Environ Pollut A. 34(2):171-190. https://doi.org/10.1016/0143-1471(84)90056-4

Vu TV, Delgado-Saborit JM, Harrison RM. 2015. Review: particle number size distributions from seven major sources and implications for source apportionment studies. Atmos Environ. 122:114-132. https://doi.org/10.1016/j.atmosenv.2015.09.027 
Wagner EC. 1939. Effects of certain insecticides and inert materials upon the transpiration rate of bean plants. Plant Physiol. 14(4):717-735. https://doi.org/10.1104/pp.14.4.717

Zafar N, Athar M, Iqbal MZ, Shafiq M. 2016. Effect of diesel generator exhaust pollutants on growth of Vinca rosea and Ruellia tuberosa. J Appl Sci Environ Manage. 20(4):11911197.

https://doi.org/10.4314/jasem.v20i4.35
Zeb S, Iqbal M, Shafiq M, Athar M. 2017. The effect of particulate matter on stomatal clogging in certain roadside plants of Karachi: Pakistan. Scientia Agriculturae. 17(3):98-104.

Zia-Khan S, Spreer W, Pengnian Y, Zhao X, Othmanli H, He X, Müller J. 2015. Effect of dust deposition on stomatal conductance and leaf temperature of cotton in northwest China. Water-SUI. 7(1):116-131.

https://doi.org/10.3390/w7010116 